\title{
EXPRESSION AND ANALYSIS OF SEISMIC DISASTER INFORMATION BASED ON KML
}

\author{
Lin Yuxuan ${ }^{1}$,Wang Shitai ${ }^{*}$ \\ ${ }^{1}$ School of surveying, mapping and geographic information, Guilin university of technology, Guilin, Guangxi
}

KEY WORDS: Google Earth,KML,Arcgis,Visual Basic,Earthquake,3D model

\begin{abstract}
:
The display and recognition of geographical features based on KML and Google Earth/Google Maps provide possibilities for the visualization and analysis of earthquake disasters.In this paper, compile and generate the corresponding point and face KML files of the disaster information of Guangxi Zhuang Autonomous Region in January through the Visual Basic custom script.The KML files realize information display, query and analysis in Google Earth,and combine with Arcgis's topography, elevation and image information of feature points to carry out multi-information source analysis and realize the interpretation and analysis of the current situation of earthquakes, which can provide some reference information for the monitoring and evaluation of earthquakes.
\end{abstract}

\section{INTRODUCTION}

\subsection{The Origin of KML}

KML (Keyhole Markup Language) is a coding specification developed by Google, based on XML (eXtensible Markup Language) grammar and file format, used to describe and preserve geographic information such as point, line, surface, 3D model, etc ${ }^{[1]}$. It can be displayed and recognized by Google Earth and Google Maps. Google Earth and Google Maps process KML files in a similar way as Web browsers process XML and HTML files. Like HTML, KML uses tags, names, and so on that contain attributes to determine how it is displayed $^{[2-6,8]}$. Now KML language has become an international standard.With the rapid development of information industry such as remote sensing and geographic information, the emergence of KML just satisfies the media carrier relationship between computer and satellite images, compresses the original large storage capacity of information into a small capacity and can reflect the information in Google Earth, and improves people's image information processing. It greatly reduces the running memory of the computer. Users also experience that the use of Google Earth has brought great convenience to related work. At the same time, it also speeds up the related research of Google satellite image.By focusing on natural disaster data analysis and disaster assessment, Google Earth can not only express the three-dimensional location and distribution range of disasters in space, but also express the development process and impact degree of disasters in time domain $^{[7]}$. Therefore, the use of KML to store geospatial data information of terrain objects and the application of XML hypertext markup language to the Google Earth client can provide great convenience for disaster analysis, assessment and prediction.

\section{FUNCTIONS AND MARKUP GRAMMAR RULES OF KML}

\subsection{Functions of KML}

(1) Be able to mark the location of the annotations and icons, and be able to overlay images and display three-dimensional objects on Google Earth;
(2) It can create different perspectives for the geographical characteristics of a region;

(3) The ability to write HTML descriptions of geographic features, including embedded and hyperlinks, and the ability to group geographic features using folders;

(4) It can specify the display style of geographical features and dynamically acquire and modify KML text format.

\subsection{KML Grammar Rules}

(1) KML uses case-sensitive closed tags.

(2) When KML uses compound labels, the first English word should be capitalized, and if it uses a single label, no capitalization is required.

(3) When using KML tags, they must be nested accurately and strictly refer to HTML hypertext markup language grammar norms

(4) There is only one root tag in the KML document.

(5) KML should be enclosed in quotation marks when declaring the attributes of geographical elements.

(6) CRLF (carriage return) in KML is similar to line break $<$ br $>$ in HTML hypertext markup language, but it shows inserting new lines.

(7) KML is similar to HTML hypertext markup language in the use of annotations, which can be seen more intuitive.

\subsection{KML Markup Type}

KML can be divided into two basic types: one is compound tag, the other is single tag. These tags have common characteristics, they are all written in English, but the difference is that the beginning letters of composite tags should be capitalized, and a single tag needs lowercase, and a single tag can not exist alone, it must be attached to the composite tag, and the composite tag can be used as the parent element of other tags.

In KML text format, the header of the XML file: <? XML version $=" 1.0 "$ encoding $=$ "UTF-8"?>

KML Spatial Definition Access's Internal Information File Web Site: <kmlxmlns "http://www.opengis.net/kml/2.2" xmlns: gx= "http://www.google.com/kml/ext/2.2">.

*Corresponding author: Wang Shitai - E-mail: 85282788@qq.com

Fund projects: Basic Competence Promotion Project for Young and Middle-aged Teachers in GuangXi Universities: KY2016YB823

GuangXi Natural Science Foundation: 2018GXNSFAA281279 


\section{VB6 (VISUAL BASIC) SCRIPT COMPILATION AND IMPLEMENTATION OF KML}

\subsection{Introduction to Script Usage}

This paper compiles and generates KML at any four points. The implementation process is shown in Figure 1. KML is generated from the region drawn by the minimum and maximum longitude and latitude values of Guangxi region and demonstrates earthquake disaster information. KML was generated by sequential input $(104.446656694,20.869762994,0)$ $(112.055282347,20.869762994,0)(112.055282347,26.38885369$ $5,0)(104.446656694,26.388853695,0)$.

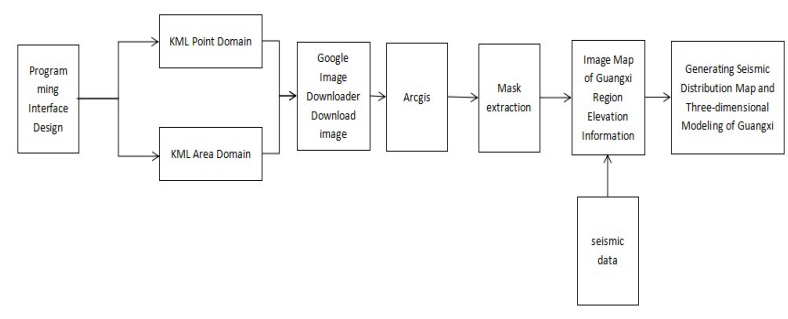

Figure 1. flow chart

\subsection{By Generating KML Area Content Fragments}

$<$ ? XML version = "1.0" encoding $=$ "UTF-8"? $>$

$<\mathrm{kmlxmlns}=$ "http://www.opengis.net/kml/2.2"

$\mathrm{xmlns:gx="http://www.google.com/kml/ext/2.2">}$

$<$ Document $>$

$<$ Style id="s55151641">

$<$ LineStyle $>$

$<$ color $>$ ff0000ff $<$ /color $>$

$<$ width $>1</$ width $>$

$</$ LineStyle $>$

$<$ PolyStyle $>$

$<$ color $>40$ ff $0000</$ color $>$

$<$ PolyStyle $>$

$<$ Style $>$

$<$ Folder $>$

$<$ name $>$ task scope $<$ name $>$

$<$ Placemark $>$

$<$ name $>$ temporary location. $\mathrm{KML}</$ name $>$

$<$ description/>

$<$ styleUrl $>$ \#s55151641</styleUrl $>$

$<$ Polygon $>$

$<$ tessellate $>1</$ tessellate $>$

$<$ outerBoundary Is $>$

$<$ LinearRing $>$

$<$ coordinates $>$

104.446656694, 20.869762994, 0//(Value 1 entered in the text box of the program interface)

$112.055282347,20.869762994,0 / /($ Number 2 entered in the text box of the program interface)

$<$ Placemark $>$

$<$ Folder $>$

$</$ Document $>$

$</ \mathrm{kml}>$

\subsection{Generate corresponding KML point domain content} fragments
$<$ Style id="s1292843445">

$<$ IconStyle $>$

$<$ scale $>1</$ scale $>$

$<$ Icon $><$ href $>$ http://maps.google.com $/$ mapfiles $/$ kml/paddle/redcircle.png $</$ href $>$

$</$ Icon $>$

$</$ IconStyle $>$

$</$ Style $>$

$<$ name $>119.3423424,18.44253453</$ name $>/ /$ (value entered in text box of program interface)

$<$ description/>

$<$ styleUrl $>$ \#s1292843445</styleUrl $>$

$<$ Point $>$

$<$ coordinates $>$

104.446656694, 20.869762994, 0//(Number entered in text box of program interface)

$</$ coordinates $>$

$<$ Point $>$

$<$ Placemark $>$

$<$ Placemark $>$

$</$ Folder $>$

$<$ Document $>$

$</ \mathrm{kml}>$

The four input points accurately locate the maximum values in the four directions of southeast and northwest of Guangxi region, covering the region in the local image as shown in Figure 2. Then the KML area file is programmed and imported into Google Earth to download the image elevation information of this area. Then it is imported into Arcgis, and the default WGS84 coordinates are selected in Arcgis. The format of the Guangxi area. SHP is also put into Arcgis to show as shown in Figure 3. This part of the coverage is the vector of Guangxi. The overlapping part of quantum format and image is extracted by AcrToolbox and Spatial Analysis tool. After the extraction, the mask is extracted as shown in Figure 4.

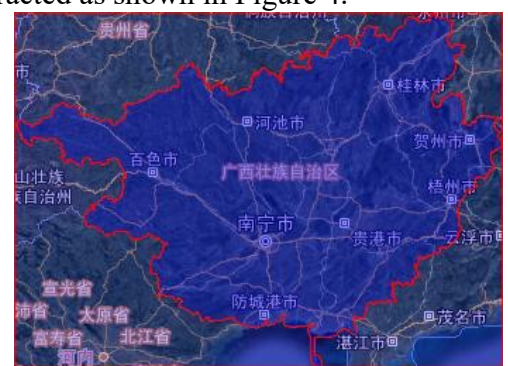

Figure 2. covers the rectangular area with the minimum and maximum longitude and latitude in the western region

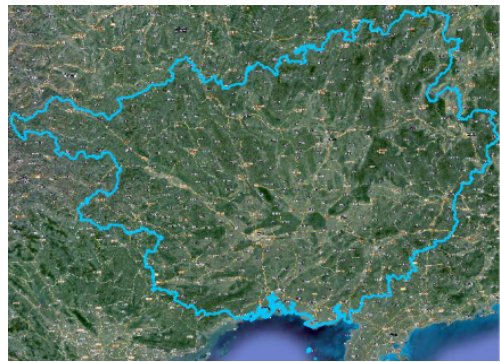

Figure 3. shows the SHP format of guangxi region 


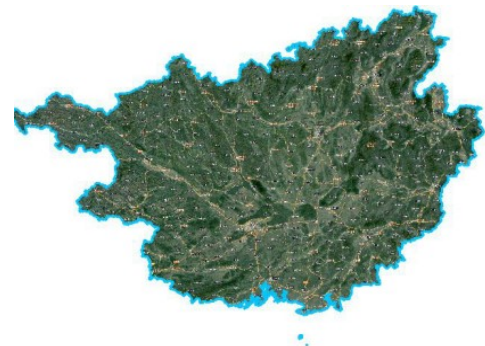

Figure 4. The image of guangzhou district taken by SHP format mask

Then the seismic data of Guangxi region from November 8, 2018 to December 8, 2018 are imported into Arcgis (data source from seismic science data sharing center (http:// data earthquake.cn)) as shown in Table 1.Add this data and display the generated map. The earthquakes that occurred in Guangxi in one month are shown in Figure 5 (plane map).

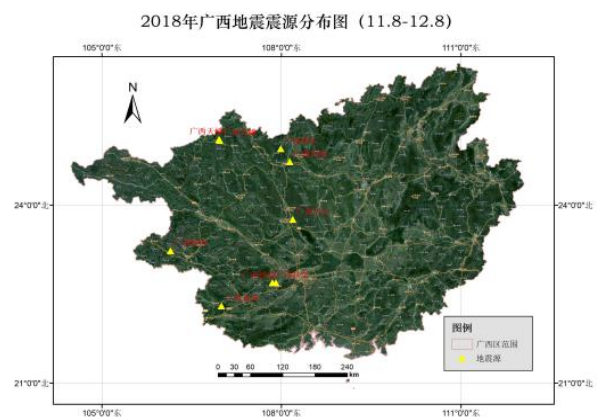

Figure 5. Earthquake distribution location in guangxi region

In order to better observe the location of the Seismic source and the magnitude of the Seismic source, different colors are used to display the place names as shown in Figure 6 and scatter point Figure 7 . The magnitude of the earthquake is shown by the size of the markers.

\begin{tabular}{|c|c|c|}
\hline 符号 & 值 & 标注 \\
\hline & 〈标题〉 & 参考地点 \\
\hline & 广西天峨 & 广西天峨 \\
\hline & 广西扶绥 & 广西扶绥 \\
\hline & 广西河池 & 广西河池 \\
\hline & 广西环江 & 广西环江 \\
\hline & 广西靖西 & 广西靖西 \\
\hline 0 & 广西龙州 & 广西龙州 \\
\hline & 广西马山 & 广西马山 \\
\hline
\end{tabular}

Figure 6. Shows place names

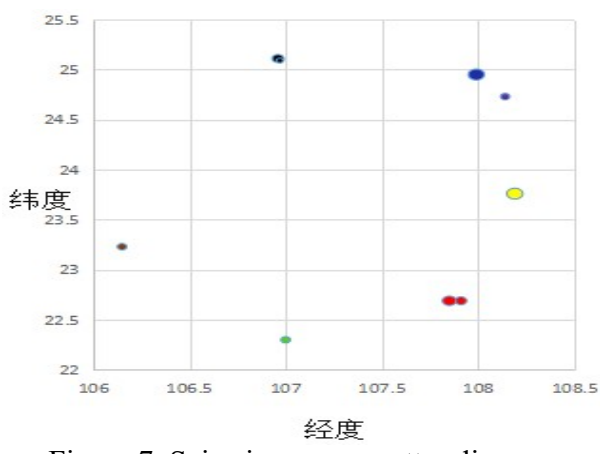

Figure 7. Seismic source scatter diagram
The magnitude of the earthquake is shown by the size of the markers. The DEM (Data Elevation Model) of the Guangxi region is displayed. It is shown that the elevation ratio of the model is $1: 1000$ and the focal depth ratio is 1:5000. Figure. 8, the three-dimensional data elevation model for observing elevation information through color is shown in Figure. 9.

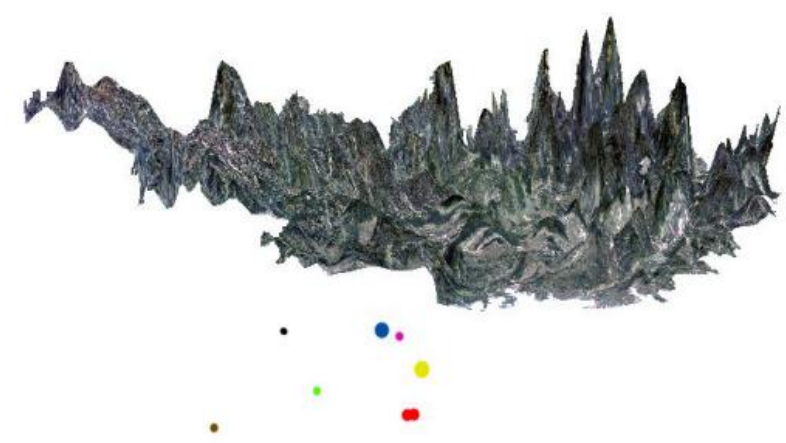

Figure 8. 3D model and focal depth

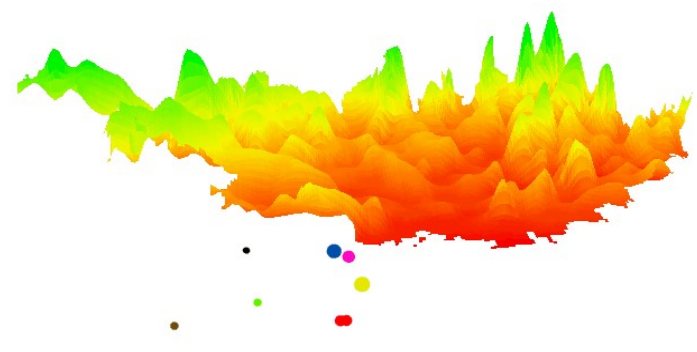

Figure 9. Three-dimensional model of elevation color

\section{CONCLUDING REMARKS}

In this paper, the information of various Geomorphology, topography and topographic changes and earthquakes in Guangxi can be visually displayed by the three-dimensional model. It can be seen that most of the earthquakes monitored in November 2018 occurred in the mountainous areas of Western Guangxi. The depth and magnitude of the source can be directly observed on the map, which provides a reliable reference for seismic analysis. There are many kinds of KML compiling languages. This paper only chooses one of them, Visual Basic (VB6), to compile and process. In order to ensure the correctness of the generated KML files, this paper loads the target range images according to Google Earth software and detects them. Through image recognition and disaster analysis of earthquake-related information, this paper provides a convenient and intuitive way to understand the location and magnitude characteristics of earthquakes. With the continuous development of Google Earth, the role of KML will become more and more prominent in the future. 
The International Archives of the Photogrammetry, Remote Sensing and Spatial Information Sciences, Volume XLII-3/W10, 2020 International Conference on Geomatics in the Big Data Era (ICGBD), 15-17 November 2019, Guilin, Guangxi, China

\begin{tabular}{|c|c|c|c|c|c|c|}
\hline $\begin{array}{c}\text { Date of earthquake } \\
\text { occurrence }\end{array}$ & $\begin{array}{l}\text { longitu } \\
\text { e }\left(^{\circ}\right)\end{array}$ & $\begin{array}{l}\text { titude ( } \\
\circ)\end{array}$ & $\operatorname{depth}(\mathrm{km})$ & Magnitude (M) & $\begin{array}{l}\text { Reference } \\
\text { site }\end{array}$ & Event type \\
\hline 2018/12/1 20:35 & 106. 15 & 23.23 & 7 & ML0. 8 & Jingxi & Natural earthquakes \\
\hline 2018/11/29 20:34 & 108. 19 & 23.76 & 6 & ML1. 5 & Mashan & Natural earthquakes \\
\hline 2018/11/29 20:16 & 107. 91 & 22.69 & 6 & ML1. 1 & Fusui & Natural earthquakes \\
\hline $2018 / 11 / 28 \quad 8: 07$ & 106. 96 & 25.11 & 6 & ML0. 4 & Tian E & Natural earthquakes \\
\hline $2018 / 11 / 27 \quad 14: 56$ & 108.14 & 24.73 & 6 & ML0. 8 & Hechi & Natural earthquakes \\
\hline 2018/11/27 9:06 & 106. 97 & 25.09 & 6 & ML0. 6 & Tian E & Natural earthquakes \\
\hline $2018 / 11 / 24 \quad 15: 51$ & 107 & 22.3 & 4 & ML0. 8 & Longzhou & Natural earthquakes \\
\hline $2018 / 11 / 24 \quad 15: 47$ & 107.85 & 22. 69 & 6 & ML1. 2 & Fusui & Natural earthquakes \\
\hline $2018 / 11 / 24 \quad 10: 13$ & 107.99 & 24.95 & 6 & ML1. 4 & Huan jiang & Natural earthquakes \\
\hline
\end{tabular}

Table 1 earthquake occurred in guangxi region from November 8, 2018 to December 8, 2018

\section{REFERENCES}

Cha Mingsheng, Xu Jiaqing. Geographic data representation based on KML [J]. Sichuan Forest Survey and Design. 2008.

Han Bohan. Research and Implementation of Electronic Map Information System for Thermal Power Plant [D]. Yanshan University. 2012.

Li Runsheng, Zhai Huinan. GPS-based positioning accuracy analysis of Google Earth [J]. Image technology. 2011.

Xiao Gang. Infectious Disease Monitoring and Early Warning GIS System Based on Google Platform [D]. University of Electronic Science and Technology. 2011.

Xu Huanxiang. Research on GLOBEC Data Online Map Service Based on Open Source Software [D]. Shandong University of Science and Technology. 2008.

$\mathrm{Zu}$ Lijun, Ekai. Research on ADCP Data Demonstration Technology Based on Google Earth [J]. People's Yangtze River People. 2015.

Zhao Zhiqi, Zhang Hongwu. Preliminary Study on the Application of Google Earth KML in Natural Disaster Analysis [J]. Survey Science and Technology. 2012.

Zeng Jiangang, Miaofang, Ye Chengming. Research on spatial database based on GML/KML [J]. Computer and digital engineering. 2009. 